Proceedings of the International Symposium on Physics of Materials (ISPMA 14), September 10-15, 2017, Prague

\title{
Investigation of Mechanical Properties and Microstructure of Non-Commercial Magnesium Alloy Prepared by Extrusion and ECAP
}

\author{
M. Zemková ${ }^{a, *}$, J. Bohlen ${ }^{b}$, J. ČAPeK ${ }^{a}$, B. Hadzima ${ }^{c}$, R. Král ${ }^{a}$ And P. Minárik ${ }^{a}$ \\ ${ }^{a}$ Charles University, Department of Physics of Materials, Prague, Czech Republic \\ ${ }^{b}$ Helmholtz-Zentrum Geesthacht, Magnesium Innovation Center, Geesthacht, Germany \\ ${ }^{c}$ University of Žilina, Research Center, Univerzitná 8215/1, Žilina, Slovak Republic
}

\begin{abstract}
Extruded magnesium alloy containing yttrium and neodymium, was processed by equal channel angular pressing (ECAP). Microstructure and mechanical properties were investigated in samples prepared by one (1P), two $(2 \mathrm{P})$, four (4P) and eight (8P) ECAP passes. Microstructure observations were performed by scanning electron microscope equipped with EBSD camera. The mechanical strength of the samples was evaluated by compression deformation tests in the processing direction $(X)$ and in the transverse direction $(Y)$. Additionally, an effect of solid solution treatment of the as-extruded material on the precipitation processes during ECAP was investigated. The results showed that ECAP significantly improves the mechanical properties of the investigated alloy gradually with the increasing number of passes through grain refinement and severe precipitation. It was shown that solute solution treatment prior to the ECAP has no effect on the mechanical properties.
\end{abstract}

DOI: 10.12693/APhysPolA.134.905

PACS/topics: 81.05.Bx, 81.40.Gh, 81.40.Cd

\section{Introduction}

Magnesium alloys have become the subject of intensive investigations in the last decade. Increasing the participation of light alloys, such as aluminium or magnesium alloys, especially in the automotive and aerospace industries is crucial for significant weight saving. Weight reduction is the most cost effective option for significant decrease of fuel consumption and $\mathrm{CO}_{2}$ emission [1]. Anyhow, $\mathrm{Mg}$ is useful in many products that benefit from its lightweight, e.g. hobby equipment, communication engineering, etc.

One of the most successful Mg alloys based on the MgRE system is WE43, containing 4 wt.\% of yttrium and 3 wt.\% of neodymium. There are many papers devoted to severe plastic deformation (SPD) with artificial aging of magnesium alloyed by rare earth elements. They indicate improvements of the mechanical properties (e.g. strength and ductility) of such alloys [2-5]. Moreover, WE43 alloy is considered as one of the most perspective for medical applications, particularly for manufacture of biodegradable implants. In this investigation, we combined the advantages of conventional extrusion and well-known SPD process equal channel angular pressing ECAP to improve the strength of non-commercial Mg4Y-3Nd alloy (WN43). Pure neodymium was used instead of the rare earth mischmetal, because among all rare earth elements it has the most beneficial effect on the corrosion resistance of $\mathrm{Mg}$ alloys [6]. ECAP is a technique introducing very large strains to the material. The

*corresponding author; e-mail: maria.zemkova@mff.cuni.cz resulting microstructure usually includes equiaxed ultrafine grains and a high density of lattice defects [7]. Such refined microstructure has a capability to improve the strength of the metallic materials, due to grain boundary strengthening. Moreover, due to the large strain introduced during ECAP, the intermetallic phases presented in the microstructure, can be fragmented into the smaller pieces [8] and additionally increase the strength of the material.

This paper reports the evolution of microstructure and mechanical properties of WN43 magnesium alloy processed by conventional extrusion followed by ECAP.

\section{Material and experiments}

The investigated alloy WN43 (in wt.\%: $3.46 \% \mathrm{Y}$, $3.53 \% \mathrm{Nd}, 0.034 \% \mathrm{Fe}, 0.004 \% \mathrm{Cu}, 0.001 \% \mathrm{Ni}$ and balance $\mathrm{Mg}$ ) was conventionally casted. Composition of the alloy was identified by spark emission spectroscopy. Afterwards, the ingot was processed by hot extrusion at $T=350{ }^{\circ} \mathrm{C}$ with an extrusion ratio $E R=30$ and a constant ram speed of $1 \mathrm{~mm} / \mathrm{s}$. Prior to the extrusion, homogenization annealing at $400^{\circ} \mathrm{C}$ for $16 \mathrm{~h}$ was performed. The annealing temperature resulted in homogenization of the material, but did not result in complete dissolution of all secondary phase particles. ECAP was performed at the temperature range of $290-330^{\circ} \mathrm{Cand}$ the ram speed of $5-10 \mathrm{~mm} / \mathrm{min}$ with internal angle of $\Theta=90^{\circ}$ and corner angle $\psi=0^{\circ}$. Molybdenum disulphide grease was used as a lubricant. Six conditions of processed material were chosen for investigation - as-extruded (Ex), after one pass of ECAP (1P), two passes (2P), four passes (4P), eight passes $(8 \mathrm{P})$ and $8 \mathrm{P}$ condition of the sample additionally annealed at $525^{\circ} \mathrm{C}$ for $16 \mathrm{~h}$ prior to the ECAP (T4-8P). 
Characterization of microstructure was performed by scanning electron microscope (SEM) ZEISS Auriga Compact equipped with EDAX EBSD camera. The samples for SEM observation and EBSD characterization were prepared by mechanical polishing using emery papers and diamond suspensions of the grain size decreasing down to $25 \mu \mathrm{m}$ and followed by ion polishing using the Leica EM RES102 ion mill. Average grain size of all investigated samples and average Schmid factors (SF) of selected samples were calculated from the EBSD data.

Mechanical properties as a function of different numbers of ECAP passes were investigated by compression deformation tests using INSTRON 5882 deformation machine. Deformation tests were carried out in two directions - along processing direction $(X)$ and transverse direction $(Y)$. These directions were chosen to investigate possible anisotropy of the processed material. All tests were performed at the room temperature using a constant deformation rate of $1 \times 10^{-3} \mathrm{~s}^{-1}$. For deformation tests, samples of $4 \times 4 \times 5 \mathrm{~mm}^{3}$ were cut out from the billets. At least four samples were tested for each investigated condition.

\section{Results}

The microstructures of all investigated conditions of the WN43 alloy are shown in Fig. 1. Hot extrusion resulted in microstructure with uniform character of the grain size distribution. Average grain size observed in the as-extruded sample was $\sim 10 \mu \mathrm{m}$, shown in Fig. 1a. The first ECAP pass resulted in significant grain refinement, especially along the former grain boundaries. Duplex character of the grain size distribution was observed, as shown in Fig. 1b. The grain size of the small grains was $\sim 1 \mu \mathrm{m}$ but the size of large grains was up to $23 \mu \mathrm{m}$ in diameter. During subsequent ECAP passes up to $4 P$, severe fragmentation of the coarse grains occurred, resulting in almost homogeneous microstructure. However, the though, presence of much bigger grains with grain size up to $7 \mu \mathrm{m}$ was still apparent in the $4 P$ sample, as shown in Fig. 1d. The uniform distribution of equiaxed grains with average grain size of $\sim 600 \mathrm{~nm}$ was observed only after eight passes for both $8 P$ and $T 4-8 P$ conditions. The respective micrographs are shown in Figs. 1e and $f$.

As mentioned above, annealing of the investigated material prior to the extrusion did not lead to complete dissolution of all secondary phase particles. As a result, extrusion led to formation of typical stripes of particles aligned along the extrusion direction [9], see Fig. 2a. Detailed evolution of the secondary phase particles distribution after increasing the number of ECAP passes is shown in Figs. 2b-d. ECAP processing resulted in disintegration of the stripe-like formation of particles and, moreover, fragmentation and dissolution of the individual particles occurred [10].
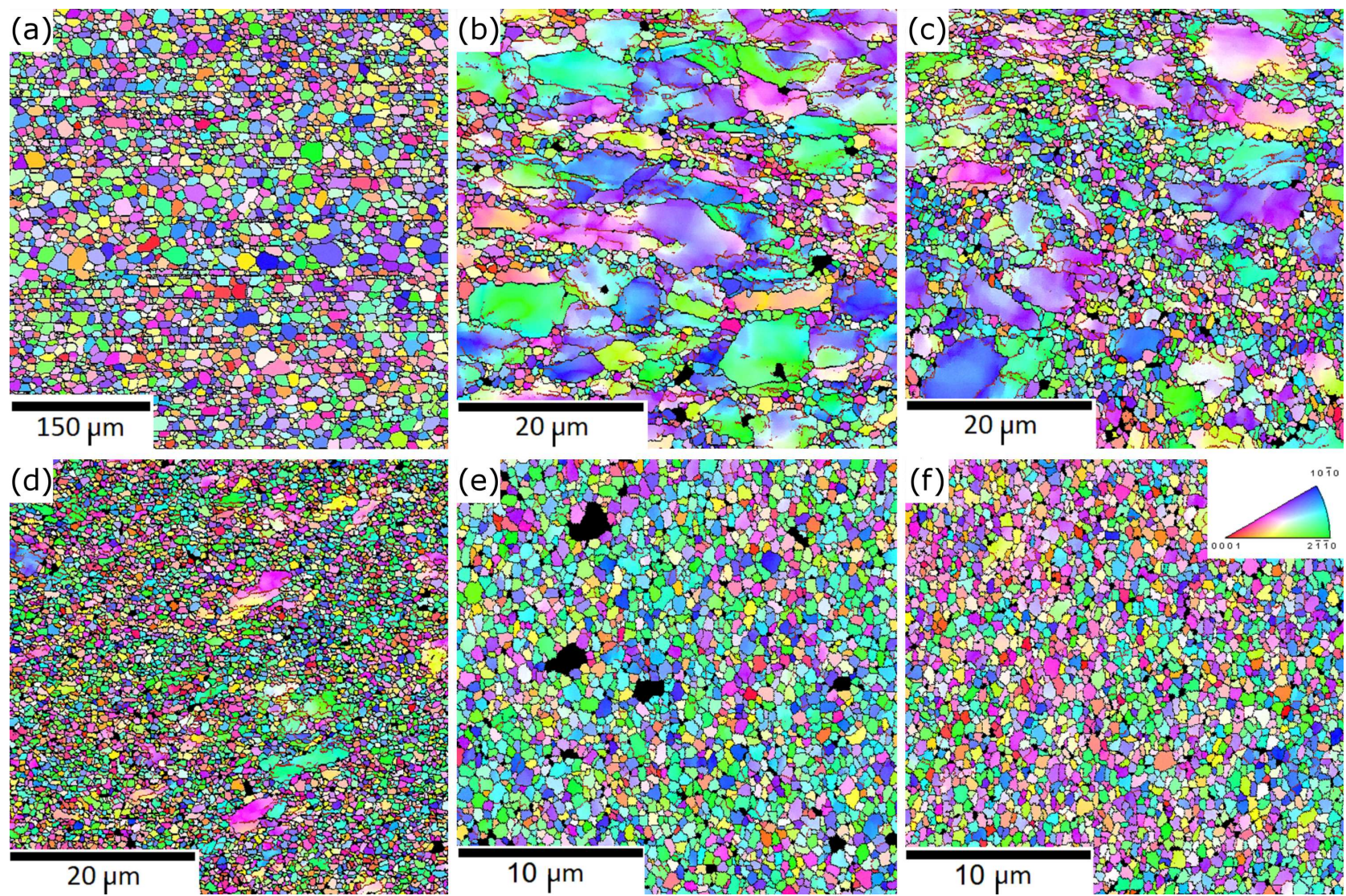

Fig. 1. EBSD micrographs of (a) Ex, (b) 1P, (c) 2P, (d) 4P (e) 8P and (f) T4-8P processed by ECAP. 

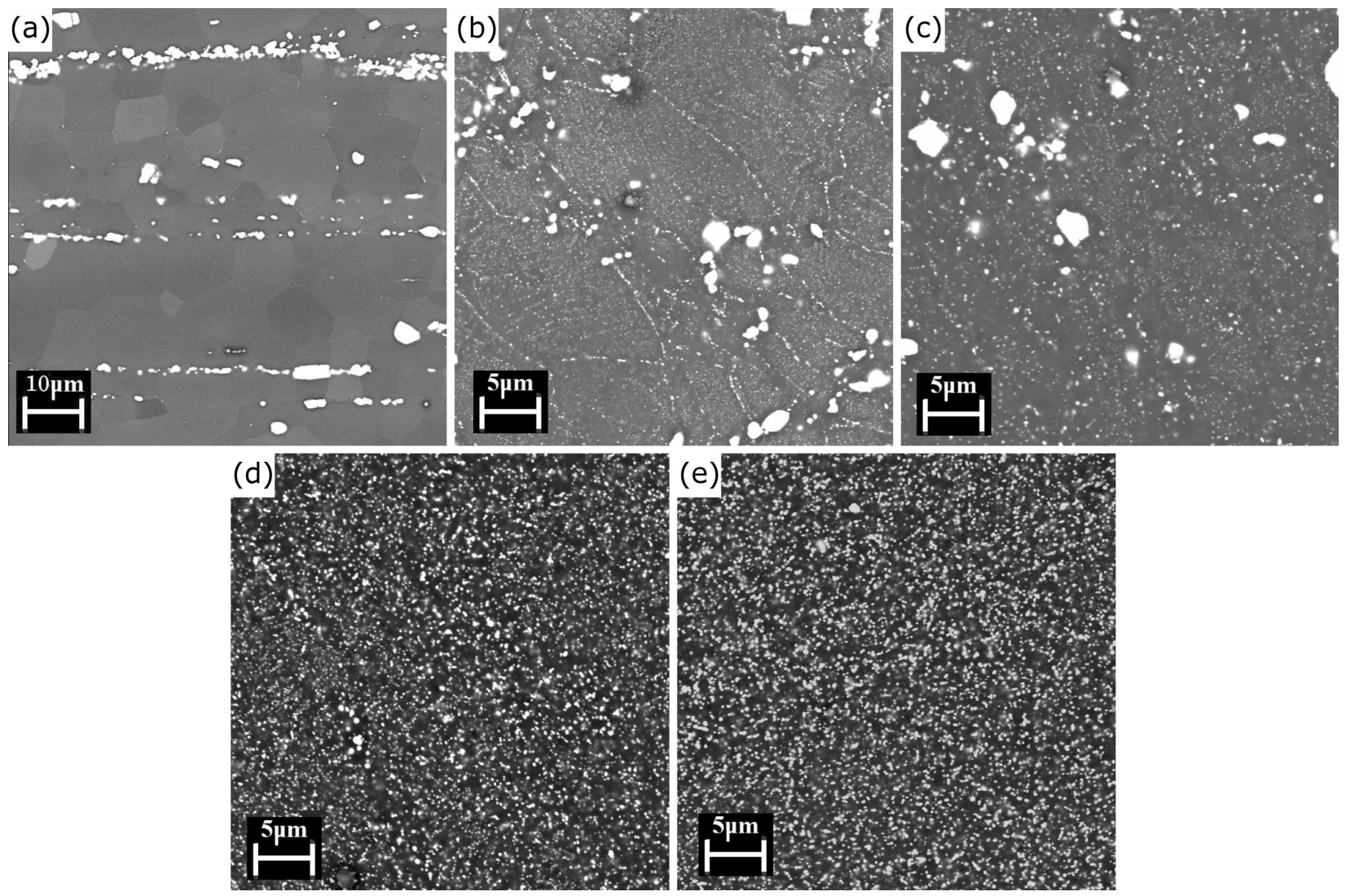

Fig. 2. Secondary phase particles distribution of WN43 processed by ECAP (a) Ex, (b) 1P, (c) 4P, (d) 8P and (e) T4-8P.

The microstructure of the $8 \mathrm{P}$ condition, see Fig. 2d, suggests that ECAP can effectively refine not only grains but also can generate homogeneous distribution of secondary phase particles in the investigated alloy due to strong plastic deformation and exposure to elevated temperature. Interestingly, comparable microstructure of the T4-8P sample can be seen in Fig. 2e. Despite the different microstructural condition of the material prior to the ECAP. This result proves that the secondary phase particles formed in this alloy dynamically dissolve and precipitate again during ECAP processing and after a sufficient number of passes a homogeneous distribution of fine particles is formed in the material regardless of the initial condition.

True stress-true strain curves measured in compression for all investigated conditions are shown in Figs. 3a and b, when deformed along $X$ direction and $Y$ direction, respectively.

The calculated values of yield compression strength (YCS) are shown in Table I. The results show that ECAP processed samples exhibit excellent mechanical properties for both deformation directions. After eight passes of ECAP, YCS of the investigated material significantly increased to $387 \pm 10 \mathrm{MPa}$ for $X$ direction, which is an improvement of more than one hundred fifty percent when compared to the as-extruded sample. On the other hand, YCS measured along $Y$ direction was only $352 \pm 10 \mathrm{MPa}$.
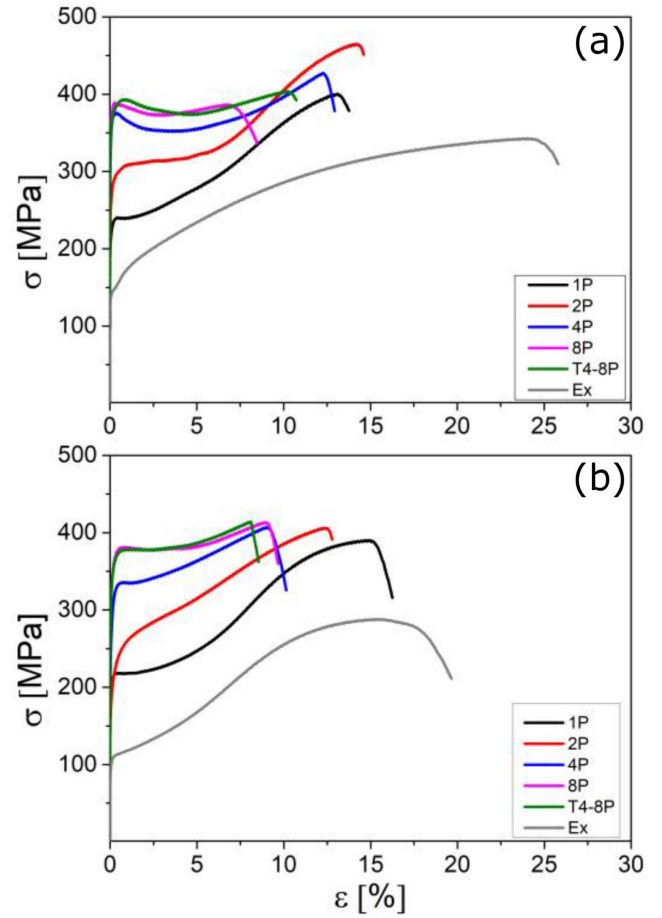

Fig. 3. The true compression stress versus true strain curves of all investigated conditions in (a) $X$ and (b) $Y$ direction. 
TABLE I

Yield compression strength measured in $X, Y$ direction of all investigated conditions.

\begin{tabular}{l|c|c}
\hline \hline & YCS $(X)$ & YCS $(Y)$ \\
\hline Ex & $146 \pm 2$ & $166 \pm 2$ \\
$1 \mathrm{P}$ & $203 \pm 15$ & $208 \pm 8$ \\
$2 \mathrm{P}$ & $284 \pm 5$ & $220 \pm 7$ \\
$4 \mathrm{P}$ & $372 \pm 9$ & $336 \pm 21$ \\
$8 \mathrm{P}$ & $396 \pm 8$ & $360 \pm 5$ \\
$\mathrm{~T} 4-8 \mathrm{P}$ & $387 \pm 10$ & $352 \pm 10$
\end{tabular}

In the Ex condition, higher values of YCS measured in the $Y$ direction resulted from the stripe-like formation of the secondary phase particles. As shown in a previous report, texture present in the as-extruded condition did not lead to any difference in YCS measured along both measured directions [9]. ECAP processing resulted in the disruption of these stripes; therefore, no difference should have been observed anymore. For a better understanding of the differences between the values of YCS measured in the $X$ and the $Y$ direction, the Schmid factor for basal slip systems was calculated for both $8 \mathrm{P}$ conditions. The average Schmid factor for the $8 \mathrm{P}$ condition when deformed is 0.26 in the $X$ direction and 0.3 in the $Y$ direction. For comparison, the SF calculated for the $\mathrm{T} 4-8 \mathrm{P}$ condition is 0.3 for the $X$ direction and 0.34 for the $Y$ direction. Because the lower SF indicates harder activation of basal slip during deformation, texture development and consequent difference in SF provide good explanation of higher strength measured in the $X$ direction in both $8 \mathrm{P}$ samples [11].

\section{Conclusions}

Evolution of microstructure and mechanical properties of non-commercial magnesium alloy WN43 processed by hot extrusion and ECAP were investigated. Significant grain refinement was observed in the investigated alloy with increasing number of ECAP passes. After eight passes UFG structure was formed with an average grain size of $\sim 600 \mathrm{~nm}$. Despite different initial conditions of $8 \mathrm{P}$ and $\mathrm{T} 4-8 \mathrm{P}$ samples prior to the ECAP, these samples exhibited the same microstructural properties. Moreover, homogeneous distribution of small secondary phase particles was observed after final stage of processing. As a result, yield compression strength increased up to $387 \pm 10 \mathrm{MPa}$ for deformation along $X$ direction and $352 \pm 10 \mathrm{MPa}$ along $Y$ direction. Difference in the strength between deformation along $X$ and $Y$ direction was attributed to distribution of secondary phase particles and texture development.

\section{Acknowledgments}

The present work is a part of the Czech Science Foundation project 16-08963S. One of the authors (M.Z.) acknowledges financial support by the Charles University Grant Agency under the grant 1109816. J.Č. acknowledges financial support by ERDF under project "Nanomaterials centre for advanced applications", Project No. CZ.02.1.01/0.0/0.0/15 003/0000485. B.H. wish to thanks for the financial support to ERDF by the project ITMS313011D011 and to Slovak grant agency by the project No. 1/0045/17.

\section{References}

[1] M.K. Kulekci, J. Adv. Manuf. Technol. 39, 851 (2008).

[2] T. Mohri, M. Mabuchi, N. Saito, M. Nakamura, Mater. Sci. Eng. A 257, 287 (1998).

[3] S.K. Panigrahi, W. Yuan, R.S. Mishra, R. DeLorme, B. Davis, R.A. Howell, K. Cho, Mater. Sci. Eng. A 530, 28 (2011).

[4] X. Huang, K. Suzuki, Y. Chino, Mater. Sci. Eng. A 538, 281 (2012).

[5] S.R. Wang, P.Q. Guo, L.Y. Yang, Y. Wang, J. Mater. Eng. Perform. 18, 137 (2009).

[6] Y. Ding, C. Wen, P. Hodgson, Y. Li, J. Mater. Chem. B 2, 1912 (2014).

[7] B. Hadzima, M. Janecek, M. Bukovina, R. Kral, Int. J. Mater. Res. 100, 1213 (2009).

[8] P. Minárik, R. Král, J. Pešička, S. Daniš, M. Janeček, Mater. Charact. 112, 1 (2016).

[9] Y. Li, K. Zhang, Y. Zhang, X. Li, M. Ma, Rare Met. 29, 317 (2010).

[10] G. Angella, P. Bassani, A. Tuissi, M. Vedani, Mater. Trans. JIM 45, 2182 (2004).

[11] P. Minárik, R. Král, J. Čížek, F. Chmelík, Acta Mater. 107, 83 (2016). 